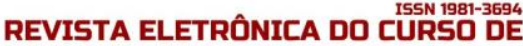

\section{O ENSINO JURÍDICO BRASILEIRO E A FORMAÇÃO DO “MEDALHÃO" MACHADIANO: EM BUSCA DE ALTERNATIVAS À LUZ DA PROFANAÇÃO AGAMBENIANA E DA CARNAVALIZAÇÃO WARATIANA}

\section{THE LEGAL EDUCATION BRAZILIAN AND TRAINING "MEDALLION" MACHADIANO: IN SEARCH OF ALTERNATIVES PROFANATION AGAMBENIANA AND CARNIVALIZATION WARATIANA}

\begin{abstract}
MAIQUEL ÂNGELo DEZORdI WERMUTH
Doutor em Direito Público pela Universidade do Vale do Rio dos Sinos (UNISINOS). Professor do Mestrado em Direitos Humanos da Universidade Regional do Noroeste do Estado do Rio Grande do Sul (UNIJUÍ) e do Curso de Graduação em

Direito da UNISINOS. madwermuth@gmail.com

Joice GRACIELA NiELSSON Doutoranda em Direito Público pela Universidade do Vale do Rio dos Sinos (UNISINOS). Professora do Curso de Graduação em Direito da Universidade Regional do Noroeste do Estado do Rio Grande do Sul (UNIJUÍ).
\end{abstract}

joice.gn@gmail.com

\section{RESUMO}

O saber jurídico das elites brasileiras- representado no texto pelo "medalhão" de Machado de Assis representa um capital simbólico que (re)produz uma organização social que cria espaços privilegiados de poder para alguns e controla e invisibiliza outros, impondo poder por meio do saber. Para tanto, o ensino jurídico sempre se voltou à "sacralização" de conceitos e institutos, implicando o afastamento de uma compreensão emancipatória do fenômeno jurídico, abordado de forma asséptica e dogmática, separando os "iniciados" na ciência do direito dos "não iniciados". Nesse sentido, esta pesquisa realizada a partir do método fenomenológico objetiva discutir, a partir da ideia de profanação cunhada pelo filósofo italiano Giorgio Agamben, a possibilidade de um "novo uso" do ensino jurídico, capaz de subverter, pela via da resistência e da carnavalização waratiana, o modelo tradicional da sacralidade, rompendo 0 nexo historicamente estabelecido entre saber e poder.

Palavras-chave: Brasil; Ensino jurídico; Estrutura social; Medalhão; Profanação.

\begin{abstract}
The legal knowledge of Brazilian elites represented in the text by "Medallion" of Machado de Assis - is a symbolic capital that (re) produces a social organization that creates privileged positions of power for some and controls and rather invisible others, imposing power by know. Thus, the legal education always turned to the "sacredness" of concepts and institutes, involving the removal of an emancipatory understanding of legal phenomenon, approached in aseptic and dogmatic form, separating the "start" right science at the "uninitiated". In this sense, this research - carried from the phenomenological method - aims to discuss, from the desecration idea coined by the Italian philosopher Giorgio Agamben, the possibility of a "new use" of legal education, able to subvert, the path of resistance and waratiana carnivalization, the traditional model of sacredness, breaking the nexus historically established between knowledge and power
\end{abstract}

Keywords: Brazil; Legal education; Social structure; medallion; profanation; 


\section{SUMÁRIO}

INTRODUÇÃO; 1 UM OLHAR HISTÓRICO SOBRE A FORMAÇÃO DO JURISTA “MEDALHÃO” NO BRASIL; 2 PROFANANDO O SAGRADO: NOTAS SOBRE A (NECESSÁRIA) CARNAVALIZAÇÃO DO ENSINO JURÍDICO BRASILEIRO; CONCLUSÃO; REFERÊNCIAS.

\section{INTRODUÇÃO}

O ensino jurídico brasileiro e seu comprometimento com a estruturação e manutenção de relações de saber-poder que se perpetuam ao longo da história de nossa terrae brasilis, ao distanciar bacharéis/sujeitos privilegiados dos meros indivíduos "comuns" tem sido objeto de análise ao longo de nossa trajetória. Machado de Assis, com sua sagacidade e ironia peculiar denunciava este quadro já nos primórdios da história universitária do país, comprometida com a formação dos bacharéis/juristas - personificados pela figura dos "medalhões" - destinados a ocupar cargos públicos de mando e, consequentemente, zelar pela manutenção do status quo e do conservadorismo. Este modelo, guardadas as peculiaridades de cada momento histórico, se perpetuou e ainda hoje domina o ensino jurídico, cujo saber representou e ainda representa um capital simbólico responsável pela manutenção e reprodução de um modelo de organização social estamental.

Neste sentido, o presente ensaio pretende traçar uma breve investigação sobre o processo histórico de constituição do ensino jurídico no Brasil, metaforicamente abordado a partir da figura do "medalhão", cunhado por Machado de Assis no conto "Teoria do Medalhão" em 1881. O Medalhão machadiano, enquanto bacharel/jurista típico da história brasileira é o fruto de um ensino jurídico asséptico, castrante, supostamente neutro, desvinculado de originalidade, descomprometido com a efetividade do direito e com a sociedade na qual está inserido. Este jurista é tomado pelo senso comum teórico - denunciado por Warat - e representa o ápice de um saber que "sacraliza" conceitos e institutos a fim de atender à perpetuação do vazio, do nada jurídico.

A par da constatação de tal cenário, a segunda parte deste ensaio aponta para a ideia de profanação cunhada pelo filósofo italiano Giorgio Agamben como condição de possibilidade de subversão, pela via da resistência, da sacralidade do ensino jurídico. Esta profanação poderia se dar por meio da "carnavalização" do ensino jurídico, proposta por Luis Alberto Warat, a qual, mediante um ensino comprometido com a ideia do “jogo" - ou seja, do deslocamento, da 
O ENSINO JURÍDICO BRASILEIRO E A FORMAÇ̃̃O DO “MEDALHÃO" MACHADIANO: EM BUSCA DE ALTERNATIVAS A LUZ DA PROFANAÇÃO AGAMBENIANA E DA CARNAVALIZAÇÃO WARATIANA

MAIQUEL ÂNGELO DEZORDI WERMUTH JOICE GRACIELA NiELSSON

erotização, da diversificação, do deboche e do conflito - pode se transformar em um modelo emancipador, capaz de subverter a ordem lógica de formação dos "medalhões".

A construção do artigo será orientada pelo método fenomenológico-hermenêutico, inspirado nas lições de Martin Heidegger ${ }^{1}$ e Hans-Georg Gadamer ${ }^{2}$, considerando-se que o tema (ensino jurídico) se encontra diretamente relacionado ao contexto no qual os pesquisadores (autores do artigo) estão inseridos, uma vez que professores de cursos de graduação e pósgraduação. Portanto, não é possível e tampouco concebível a cisão entre os sujeitos (os pesquisadores) e o objeto de estudo do artigo. E mais: na perspectiva do círculo hermenêutico, no qual a pré-compreensão antecede a compreensão, que está conectada à interpretação e aplicação do Direito pela via do ensino jurídico, o mencionado contexto - de crise do ensino do Direito - deverá receber a atribuição de sentido, para viabilizar a construção de uma resposta hermeneuticamente orientada.

\section{UM OLHAR HISTÓRICO SOBRE A FORMAÇÃO DO JURISTA “MEDALHÃO” NO BRASIL}

A forma como historicamente se estrutura o ensino do Direito no Brasil está diretamente relacionada à imposição de poder por meio do saber ${ }^{3}$. 0 saber jurídico das elites da sociedade brasileira sempre representou um capital simbólico no sentido de (re)produzir um modelo de organização social pautado por uma rígida hierarquização, que pressupunha a criação de espaços privilegiados de poder para alguns e a viabilização de estratégias de controle e invisibilização social de determinados estratos populacionais.

O processo de construção deste saber jurídico, enquanto poder, se perpetuou no ensino jurídico, voltado à criação de uma sociedade marcada pela ausência do que José Murilo de Carvalho ${ }^{4}$ chama de cultura cívica de respeito às leis, na qual o culto ornamental das ideias e a quebra das formalidades, característica do homem cordial descrito por Sérgio Buarque de

\footnotetext{
${ }^{1}$ HEIDEGGER, Martin. A essência da linguagem. IN: A Caminho da Linguagem. Tradução de Marcia Sá Cavalcante Schuback. Petrópolis: Vozes, 2003, p. 121-71.

${ }^{2}$ GADAMER, Hans-Georg. Verdade e Método: traços fundamentais de uma hermenêutica filosófica. 4. ed. Tradução de Flávio Paulo Meurer. Petrópolis: Vozes, 2002, vol. I.

${ }^{3}$ FOUCAULT, Michel. Microfísica do poder. 18. ed. São Paulo: Graal, 2003.

${ }^{4}$ CARVALHO, José Murilo. Cidadania no Brasil: o longo caminho, Rio de Janeiro: Civilização Brasileira, 2002.
} 
O ENSINO JURÍDICO BRASILEIRO E A FORMAÇ̃̃O DO “MEDALHÃO" MACHADIANO: EM BUSCA DE ALTERNATIVAS A LUZ DA PROFANAÇÃO AGAMBENIANA E DA CARNAVALIZAÇÃO WARATIANA

MAIQUEL ÂNGELO DEZORDI WERMUTH JOICE GRACIELA NIELSSON

Holanda $^{5}$, também marcaram a formação dos juristas nacionais. No entanto, a ineficácia do direto, daí decorrente, longe de mera característica natural da formação social brasileira, se transformou em instrumento favorável à manutenção das relações de poder que caracterizavam o status quo e o conservadorismo.

Esta é a denúncia feita por Machado de Assis, em seu conto "Teoria do medalhão", publicado pela primeira vez em 1882, em um livro intitulado Papéis avulsos. O conto narra a história de um pai que dá conselhos ao filho que acaba de atingir a maioridade, e o ensina a se tornar um medalhão:

Alguns costumam renovar o sabor de uma citação intercalando-a numa frase nova, original e bela, mas não te aconselho esse artifício: seria desnaturar-lhe as graças vetustas. Melhor do que tudo isso, porém, que afinal não passa de mero adorno, são as frases feitas, as locuções convencionais, as fórmulas consagradas pelos anos [...] Quanto à utilidade de um tal sistema, basta figurar uma hipótese. Faz-se uma lei, executa-se, não produz efeito, subsiste o mal. Eis aí uma questão que pode aguçar as curiosidades vadias, dar ensejo a um inquérito pedantesco, a uma coleta fastidiosa de documentos e observações, análise das causas prováveis, causas certas, causas possíveis, um estudo infinito das aptidões do sujeito reformado, da natureza do mal, da manipulação do remédio, das circunstâncias da aplicação; [...] Tu poupas aos teus semelhantes todo esse imenso arranzel, tu dizes simplesmente: Antes das leis, reformemos os costumes! - E esta frase sintética, transparente, límpida, tirada ao pecúlio comum, resolve mais depressa o problema, entra pelos espíritos como um jorro súbito de sol ${ }^{6}$.

0 parágrafo inicia-se, segundo Fernandes ${ }^{7}$, com a glorificação do clichê, do pensar apenas o já pensado a partir de um direito que não tenha eficácia social: "não produz efeito, subsiste o mal". Ao constatar a situação de ineficácia, o medalhão/jurista não buscará pesquisar e entender a etiologia de um determinado problema social, mas apenas enunciará um lugar comum, expressão verbal da falta de mudanças sociais, vinculando a incompetência técnica da formação jurídica ao estabelecimento e manutenção de relações estamentais de poder.

A consolidação deste quadro remonta aos primórdios do ensino jurídico no Brasil, que teve como marco fundamental a criação dos primeiros cursos jurídicos pátrios em 1827, em

\footnotetext{
${ }^{5}$ HOLANDA, Sérgio Buarque de. Raízes do Brasil. 26. ed. 28. reimpr. São Paulo: Companhia das Letras, 2007.

${ }^{6}$ MACHADO DE ASSIS. Obra completa, em quatro volumes. Org. A. Leite Neto, A. Lima Cecília, H. Jahn, Rio de Janeiro: Nova Aguilar, vol. II e IV, 2008, p. 272.

${ }^{7}$ FERNANDES, Pádua. Machado de Assis e o olhar irônico no país dos bacharéis. Revista Ética e Filosofia Política. n. 14, vol. 2, 2011.
} 
O ENSINO JURÍDICO BRASILEIRO E A FORMAÇÃO DO "MEDALHÃO" MACHADIANO: EM BUSCA DE ALTERNATIVAS A LUZ DA PROFANAÇÃO AGAMBENIANA E DA CARNAVALIZAÇÃO WARATIANA

MAIQUEL ÂNGELO DEZORDI WERMUTH JOICE GRACIELA NiELSSON

Olinda (em 1854, o curso foi transferido para Recife) e em São Paulo ${ }^{8}$, depois de um longo atraso de 327 anos de colonização portuguesa, período no qual a formação educativa e intelectual do povo brasileiro esteve a cargo principalmente dos jesuítas. Este atraso refletia, segundo Adorno ${ }^{9}$ a preocupação portuguesa com o extrativismo exploratório e, portanto, com a necessidade de manutenção dos fortes vínculos que sustentavam a dependência de nossa colônia, dos quais, a necessidade de ir estudar em Portugal era um dos mais fortes. A partir daí, os enviados para estudarem nas escolas da Europa, principalmente em Coimbra, ou eram filhos de abastados fidalgos coloniais ou altos funcionários da Igreja ou da Corte ${ }^{10}$.

Como salienta Gizlene Neder ${ }^{11}$, os bacharéis em Direito formados em Coimbra, em que pese a "contaminação" ideológica de cariz iluminista decorrente da sua formação, representavam os expoentes de uma classe "que se sustentou à base do açoite", no controle social direto e repressivo do cotidiano das classes subalternizadas, notadamente as compostas, em um primeiro momento, pelos escravos - já que a base da economia brasileira permanecia sendo a monocultura latifundiária sustentada pela mão-de-obra escrava - e, em um segundo momento, pelos espólios da escravidão. Estabelece-se, assim, com a transposição dos ideais liberais para o domínio brasileiro, a seguinte equação: afirmação dos direitos de liberdade para as classes dominantes versus manutenção da opressão sobre os setores subalternos, como decorrência da manutenção do trabalho escravo como base de sustentação das elites.

Inseridas neste contexto, as primeiras faculdades de Direito surgem no Brasil após a Independência, com a clara intenção de atender às necessidades de "constituir quadros para o aparelho governamental" e de controlar "o processo de formação ideológica dos intelectuais a serem requisitados pela burocracia estatal", como lembra Sérgio Adorno ${ }^{12}$ em seu estudo sobre o bacharelismo durante o Império. Para tanto, reproduziu-se em grande medida o enfoque adotado em Coimbra, exigindo-se, para o ingresso, que os alunos tivessem no mínimo quinze anos de idade e soubessem francês, latim, retórica, filosofia (racional e moral) e geometria, configurando-se como público alvo privilegiado os filhos das classes mais ricas do país.

\footnotetext{
${ }^{8}$ RODRIGUES, Horário Wanderlei. Ensino Jurídico: saber e poder. 1 ed. São Paulo: Acadêmica, 1988.

9 ADORNO, Sérgio França. Aprendizes do Poder: o bacharelismo liberal na política brasileira. Rio de Janeiro: Paz e Terra, 1998.

${ }^{10}$ RODRIGUES, Horário Wanderlei. Ensino Jurídico: saber e poder. 1 ed. São Paulo: Acadêmica, 1988.

11 NEDER, Gizlene. Iluminismo jurídico-penal luso-brasileiro: obediência e submissão. 2. ed. Rio de Janeiro: Revan, 2007, p. 187-188.

12 RODRIGUES, Horário Wanderlei. Ensino Jurídico: saber e poder. 1 ed. São Paulo: Acadêmica, 1988, p. 88.
} 
O ENSINO JURÍDICO BRASILEIRO E A FORMAÇ̃̃O DO “MEDALHÃO" MACHADIANO: EM BUSCA DE ALTERNATIVAS Á LUZ DA PROFANAÇÃO AGAMBENIANA E DA CARNAVALIZAÇÃO WARATIANA

MAIQUEL ÂNGELO DEZORDI WERMUTH JOICE GRACIELA NIELSSON

Formou-se assim, por meio do ensino de Direito, uma elite política que comandou e ditou os rumos do Estado Imperial, por meio de um processo que não estava voltado à formação de juristas, mas sim à formação de bacharéis que pudessem assumir os diversos cargos que a burocracia estatal ofertava, nos poderes administrativo, legislativo, judiciário. A educação jurídica, neste bojo, estava voltada ao ensino de Direito, e não ao ensino do Direito, conforme esclarece Adorno $^{13}$, reproduzindo assim “as inconsistências do liberalismo brasileiro", marcada inicialmente por um viés pragmático e tecnicista e relegando ao segundo plano um ensino jurídico crítico e reflexivo.

Deve-se salientar, a propósito, que os traços de uma sociedade essencialmente rural, não foram suplantados com o processo de urbanização do País iniciado a partir da declaração da Independência. Isso porque, com a formação dos centros urbanos, os cargos relativos à vida citadina (carreiras burocráticas, profissões liberais, etc) foram sendo paulatinamente ocupados pelos próprios aristocratas rurais e seus descendentes que, transportados para as cidades, carregaram consigo "a mentalidade, os preconceitos e, tanto quanto possível, o teor de vida que tinham sido atributos específicos de sua primitiva condição.”14. Verifica-se, portanto, uma interpenetração do ideário burguês com permanências históricas da cultura política do Antigo Regime e do escravismo, "que deu suporte a uma prática jurídico-política e a uma afetividade absolutista, que desafiaram a racionalidade do capitalismo e seu ideário, que se queria implantar." 15 .

Segundo Wolkmer ${ }^{16}$, ao analisar a formação das Academias de Direito,

[...] o processo de formação de nossas instituições destacou a estranha e contraditória confluência, de um lado, da herança colonial burocráticopatrimonialista, marcada por práticas nitidamente conservadoras; de outro, de uma tradição liberal que serviu e sempre foi utilizada, não em função de toda a sociedade, mas no interesse exclusivo de grande parcela das elites hegemônicas detentoras do poder, da propriedade privada e dos meios de produção da riqueza.

Este bacharelismo, conforme cunhado por Rodrigues ${ }^{17}$ que, já no final do Império constituía um ideal de vida conferia a quem ostentasse o tratamento de "doutor" ou "bacharel"

\footnotetext{
${ }^{13}$ RODRIGUES, Horário Wanderlei. Ensino Jurídico: saber e poder. 1 ed. São Paulo: Acadêmica, 1988, p. 162.

${ }^{14}$ HOLANDA, Sergio Buarque de. Raízes do Brasil. 26. ed. 28. reimpr. São Paulo: Companhia das Letras, 2007, p. 82.

${ }^{15}$ NEDER, Gizlene. Cultura, poder e violência. Revista Latinoamericana de Psicopatologia Fundamental. São Paulo, n. 1, 2009, p. 20.

${ }^{16}$ WOLKMER, Antônio Carlos. História do Direito no Brasil. 2. ed. Rio de Janeiro: Forense, 2001, p. 114.
} 
O ENSINO JURÍDICO BRASILEIRO E A FORMAÇÃO DO “MEDALHÃO" MACHADIANO: EM BUSCA DE ALTERNATIVAS A LUZ DA PROFANAÇÃO AGAMBENIANA E DA CARNAVALIZAÇÃO WARATIANA

MAIQUEL ÂNGELO DEZORDI WERMUTH JOICE GRACIELA NIELSSON

um lugar de destaque na vida social, e demarcava uma classe aristocrática em ascensão, como condição de possibilidade para se tornar um “medalhão” machadiano. Os cursos de direito e a formação jurídica atendiam menos a uma característica vocacional ou a uma preocupação ou sentido social e coletivo mais nobre, e muito mais à satisfação de interesses individuais e a um agir instrumental, associado ao declínio do valor do trabalho ${ }^{18}$, e à ascensão do desejo de conseguir um bom emprego com um esforço relativamente pequeno e com a real garantia de gozar de um bom prestígio social perante os pares, o típico medalhão descrito por Machado.

Esta situação perdurou pelo Segundo Reinado e adentrou a República, que nada mais fez do que manter a tradição colonial e sua estrutura estamental e as mesmas bases econômicas, passando mais do que nunca o Governo a figurar como incentivador e absorvedor dos letrados que eram incorporados aos cargos governamentais por meio do funcionalismo público, e a partir daí poderiam enriquecer ${ }^{19}$. Apesar de o ensino jurídico ser o responsável pela maioria dos bacharéis que iriam compor a elite política brasileira, não havia preocupação em construir um conhecimento que se adequasse à realidade nacional, sendo as teorias importadas sem a menor reflexão sobre seu enquadramento a um meio social peculiar ${ }^{20}$, até mesmo porque os diplomas

${ }^{17}$ RODRIGUES, Horário Wanderlei. Ensino Jurídico: saber e poder. 1 ed. São Paulo: Acadêmica, 1988.

$18 \mathrm{Em}$ relação às classes subalternizadas, em decorrência da abolição da escravatura, passou-se à necessidade de uma justificação ideológica para o trabalho obrigatório, a qual vai ser buscada a partir da concepção do trabalho enquanto elemento de ordenação da sociedade, sendo uma retribuição, pelo trabalhador, à sociedade, de tudo aquilo que ela the garante, a exemplo da segurança, dos direitos individuais, da liberdade, etc. Outrossim, estabelece-se um liame entre trabalho e moralidade, pautado na compreensão de que quanto maior a dedicação do indivíduo ao trabalho, maiores os seus atributos morais. Com efeito, o fato de o Brasil viver um momento de constituição de um mercado de trabalho "livre" no bojo do processo de implantação do capitalismo no país, redundou na ênfase dada ao ideal burguês do trabalho. $O$ indivíduo das classes subalternas neste contexto, ou era trabalhador ou era vadio e, consequentemente, perigoso, devendo, portanto, ser reprimido. CHALHOUB, Sidney. Trabalho, lar e botequim: o cotidiano dos trabalhadores no Rio de Janeiro da belle époque. 2. ed. Campinas: UNICAMP, 2001.

${ }^{19}$ Lembrando que "enriquecer, na obra de Machado de Assis, significa, normalmente, pôr-se ao abrigo do trabalho, ganhar o emprego suave de não fazer nada, nas serenas funções de capitalista." FAORO, Raymundo. Os Donos do Poder: formação do patronato Político brasileiro. 3. Ed.. São Paulo: Globo, 2001, p. 28.

20 No campo da Criminologia, por exemplo, todo o discurso jurídico brasileiro da época buscava legitimidade no pensamento europeu, no qual a Criminologia emergia enquanto ciência, com o escopo de, por meio de um discurso dotado de cientificidade - ao lado da Sociologia e da Psicologia -, garantir a hegemonia burguesa em face do movimento operário europeu. Em terrae brasilis, as teses então propaladas pela Criminologia europeia, em especial aquelas que sofriam influência do racismo-biologista de corte epistemológico lombrosiano, foram assimiladas e reelaboradas, fazendo surgir o "criminoso brasileiro", o qual "ganhou novos adereços, relacionados às teses da miscigenação racial e às elucubrações sobre a presença de ex-escravos de origem africana nas cidades brasileiras." Nesse sentido, "enquanto que na Itália e na França o discurso criminológico surgia num momento de questionamento da ordem quando se tornava inoperante o uso puro e simples da repressão -, no Brasil, tal discurso explicitava toda 
O ENSINO JURÍDICO BRASILEIRO E A FORMAÇ̃̃O DO “MEDALHÃO" MACHADIANO: EM BUSCA DE ALTERNATIVAS A LUZ DA PROFANAÇÃO AGAMBENIANA E DA CARNAVALIZAÇÃO WARATIANA

MAIQUEL ÂNGELO DEZORDI WERMUTH JOICE GRACIELA NIELSSON

significavam mais "brasões de nobreza" do que elementos propulsores de um saber científico, em uma “sociedade não rígida, mas respeitosa da hierarquia. Há a 'boa sociedade' e a sociedade comum. Entre uma e outra, o abismo do prestígio, do estilo de vida, do acesso ao mando."21.

Este continuísmo político, em termos de teoria do direito, além do argumento da tradição, era beneficiado pela postura de excluir da reflexão jurídica o problema das condições de aplicação da norma, isto é, pelo idealismo configurado em formalismo jurídico. Uma espécie de confiança do bacharel no "poder milagroso das ideias" que tinha origem, segundo Sergio Buarque de Holanda ${ }^{22}$ em um "secreto horror à nossa realidade". No plano da cultura jurídica, esse horror traduzia-se no idealismo jurídico, entendido não só como a crença em um direito autônomo em relação à sociedade, mas também como a consideração das questões sociais somente por meio dos filtros do processo judicial e da doutrina jurídica ${ }^{23}$.

No entanto, as ideias às quais a elite jurídica brasileira se apegava - conforme aponta Machado de Assis em seu “jurista medalhão" -, são aquelas de segunda ordem, em que o máximo permitido era buscar um ou outro clássico, mitologias e versos célebres na "difícil arte de pensar o pensado", na opção pelo estático, pela manutenção da ordem posta e de seus vícios, ou seja, pela conservação das regras do jogo e das cartas marcadas que representam o trunfo e a consequente vitória do medalhão, e do horror às ideias, como evidencia o presente excerto do conto machadiano: "uma vez entrado na carreira, deves pôr todo o cuidado nas idéias que houveres de nutrir para uso alheio e próprio. 0 melhor será não as ter absolutamente" 24 .

Afasta-se deste modo, qualquer esboço de originalidade, gosto ou ideia própria, em uma apologia à 'neutralidade' e ao uso e abuso de palavras sem sentido, deixando claro o espanto que a autenticidade, originalidade e conteúdo intelectual apropriado causariam naquela esfera

uma tentativa de recurso à técnica e à ciência no sentido de legitimar a regulamentação e a normatização da ordem burguesa em processo de afirmação. Tratava-se, portanto, não propriamente de uma situação de crise de hegemonia por esgotamento político, mas de uma crise de afirmação no processo de estruturação do Estado sob a forma republicana na passagem à modernidade. Começara a haver uma tendência, embora não totalmente formalizada, de localizar no Estado o monopólio da violência e da repressão, transferindo-se, assim, para as instituições policiais e judiciais, larga parcela das práticas de controle e disciplinamento anteriormente exercidas diretamente pelos senhores de escravos." NEDER, Gizlene; CERQUEIRA FILHO, Gisálio. Criminologia e Poder Político: sobre direitos, história e ideologia. Rio de Janeiro: Lumen Juris, 2006, p. 27-28.

${ }^{21}$ FAORO, Raymundo. Os Donos do Poder: formação do patronato Político brasileiro. 3. Ed.. São Paulo: Globo, 2001, p. 20-21.

${ }^{22}$ HOLANDA, Sérgio Buarque de. Raízes do Brasil. 26a . ed. São Paulo: Companhia das Letras, 1995, p. 159.

${ }^{23}$ FERNANDES, Pádua. Machado de Assis e o olhar irônico no país dos bacharéis. Revista Ética e Filosofia Política. n. 14, vol. 2, 2011.

${ }^{24}$ MACHADO DE ASSIS. Obra completa, em quatro volumes. Org. A. Leite Neto, A. Lima Cecília, H. Jahn, Rio de Janeiro: Nova Aguilar, vol. II e IV, 2008, p. 274. 
O ENSINO JURÍDICO BRASILEIRO E A FORMAÇ̃̃O DO “MEDALHÃO" MACHADIANO: EM BUSCA DE ALTERNATIVAS Á LUZ DA PROFANAÇÃO AGAMBENIANA E DA CARNAVALIZAÇÃO WARATIANA

MAIQUEL ÂNGELO DEZORDI WERMUTH JOICE GRACIELA NIELSSON

social, na qual o império do discurso constitui um elemento a mais na construção de um universo de aparência, de espetáculo, do nada. Esse “formalismo jurídico de araque”, conforme Pádua Fernandes ${ }^{25}$ é conveniente para o poder em uma cultura que não está especialmente interessada nos direitos humanos, eis que a questão dos efeitos sociais da norma jurídica, essencial a norma cuja finalidade é a garantia da dignidade humana é descartada numa abordagem formalista como denuncia Machado de Assis no excerto transcrito no início desse tópico.

Nesta árdua empreitada do "jurista medalhão", além de não the caber dar asas às curiosidades vadias, a um inquérito pedantesco, a uma coleta fastidiosa a respeito da ineficácia social das leis e do direito, outro elemento se coloca como fundamental: a conquista da notoriedade, não, é claro, por meio de ideias próprias, pelo caráter, por projetos comprometidos com o bem-estar social ou coletivo, mas sim através da constituição e ampliação de relações interpessoais e da construção de uma imagem que fosse bem vista em seu meio de convivência. Esta árdua tarefa traria a glória almejada na estrutura social do Brasil no século XIX:

Não te falei ainda dos benefícios da publicidade. A publicidade é uma dona loureira e senhoril, que tu deves requestar à força de pequenos mimos, confeitos, almofadinhas, coisas miúdas, que antes exprimem a constância do afeto do que o atrevimento e a ambição. Que D. Quixote solicite os favores dela mediante, ações heróicas ou custosas, é um sestro próprio desse ilustre lunático. 0 verdadeiro medalhão tem outra política. Longe de inventar um Tratado científico da criação dos carneiros, compra um carneiro e dá-o aos amigos sob a forma de um jantar, cuja notícia não pode ser indiferente aos seus concidadãos. Uma notícia traz outra; cinco, dez, vinte vezes põe o teu nome ante os olhos do mundo ${ }^{26}$.

Trata-se da apologia ao "homem cordial" brasileiro, conforme Sérgio Buarque de Holanda ou até mesmo a prática do “jeitinho” referida por Roberto Da Matta ${ }^{27}$, presente nos gestos largos, no espírito aparentemente folgazão, no uso exagerado dos diminutivos, que visam justamente à quebra da formalidade, para que as relações que estejam se estabelecendo passem à esfera da "amizade". Toda esta aparente gentileza e afetuosidade constituiriam uma estratégia, tanto de ascensão quanto de manutenção de uma dada posição individual ao mesmo tempo em que da própria estrutura da sociedade. É o império da máxima: "aos inimigos, a lei;

\footnotetext{
${ }^{25}$ FERNANDES, Pádua. Machado de Assis e o olhar irônico no país dos bacharéis. Revista Ética e Filosofia Política. n. 14, vol. 2, 2011, p. 59.

${ }^{26}$ MACHADO DE ASSIS. Obra completa, em quatro volumes. Org. A. Leite Neto, A. Lima Cecília, H. Jahn, Rio de Janeiro: Nova Aguilar, vol. II e IV, 2008, 282.

27 DA MATTA, Roberto. Carnavais, malandros e heróis: para uma sociologia do dilema brasileiro. Rio de Janeiro: Rocco, 1997.
} 
ISSN 1981-3694

(DOI): $10.5902 / 1981369419596$

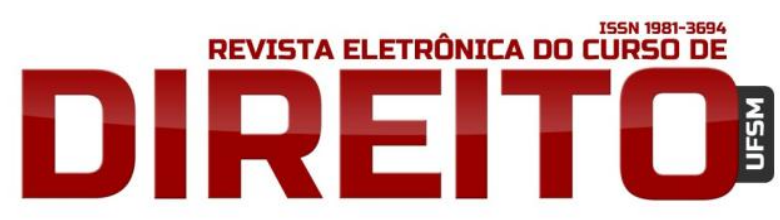

O ENSINO JURÍDICO BRASILEIRO E A FORMAÇÃO DO “MEDALHÃO” MACHADIANO: EM BUSCA DE ALTERNATIVAS À LUZ DA PROFANAÇÃO AGAMBENIANA E DA CARNAVALIZAÇÃO WARATIANA

MAIQUEL ÂNGELO DEZORDI WERMUTH JOICE GRACIELA NIELSSON

aos amigos, tudo!"28, própria de um modelo social pautado pela nítida distinção entre "pessoas” e "indivíduos", no qual o conceito de indivíduo está associado à impessoalidade, ao passo que o conceito de pessoa está associado às relações de amizade, de parentesco, de "conhecimento". Nessa relação, o indivíduo recebe o tratamento impessoal da lei, ao passo que a pessoa, por suas relações, recebe um tratamento privilegiado. Com isso, na realidade brasileira tem-se "um universo formado de um pequeno número de pessoas, hierarquizado, comandando a vida e o destino de uma multidão de indivíduos, esses que devem obedecer à lei." ${ }^{29}$.

O senso crítico e irônico de Machado de Assis ao observar os bacharéis e a cultura jurídica de seu tempo, marcada pela produção legal da ilegalidade, pela manipulação do direito para produzir efeitos contrários às finalidades da lei, e pela ineficácia social das normas jurídicas sob a apropriação privatista das regras ${ }^{30}$, revelam muito dos traços presentes ainda hoje no 'profissional do direito', e no ideal nacional do medalhão. "Ser medalhão é atingir [...] a plenitude do vazio interior" ${ }^{31}$, que no campo do direito se traduz no vazio teórico do bacharel, imediatamente preenchido pelo status quo conservador e contrário à liberdade.

\section{PROFANANDO O SAGRADO: NOTAS SOBRE A (NECESSÁRIA) CARNAVALIZAÇÃO DO ENSINO JURÍDICO BRASILEIRO}

Como salientado no tópico precedente, bacharéis em direito e medalhões se confundiam no Brasil do século XIX. No entanto, cabe questionar se este perfil se perdeu no tempo, ou as características da cultura bacharelesca, individualista, mergulhada em interesses pessoais de conquistar cargos públicos, posição privilegiada e status, e na formalização de um direito desvinculado de sua eficácia social ainda perduram nos dias atuais?

Em toda sociedade histórica e temporalmente localizada, é possível identificar alguns valores e sentimentos que exercem influências sobre as relações sociais de tal modo que ultrapassam as noções de tempo e se constituem como elementos sociais imutáveis e absolutos.

\footnotetext{
${ }^{28}$ DA MATTA, Roberto. Carnavais, malandros e heróis: para uma sociologia do dilema brasileiro. Rio de Janeiro: Rocco, 1997, p. 24.

29 DA MATTA, Roberto. Carnavais, malandros e heróis: para uma sociologia do dilema brasileiro. Rio de Janeiro: Rocco, 1997, p. 231.

${ }^{30}$ FERNANDES, Pádua. Machado de Assis e o olhar irônico no país dos bacharéis. Revista Ética e Filosofia Política. n. 14, vol. 2, 2011.

${ }^{31}$ BOSI, Alfredo. Machado de Assis: o enigma do olhar. São Paulo: Martins Fontes, 2007, p. 92.
} 
Roberto Da Matta ${ }^{32}$ encontra, no Brasil, a presença de tais elementos a-históricos em determinados ritos sociais como o carnaval, as procissões, e o questionamento hierarquizador do “você sabe com quem está falando?”.

Uma análise de como se dá o ensino jurídico no Brasil contemporâneo parece não evidenciar um grande distanciamento em relação à lógica do “medalhão" denunciada por Machado de Assis. Continua-se a prezar as relações personalíssimas em detrimento de uma lei geral que impõe a todos um tratamento igualitário, e a igualdade ainda é encarada como uma realidade remota, futurista. Em outros termos, os medalhões descritos por Machado de Assis continuam a se reproduzir à frente de nossa sociedade através do predomínio de uma ética individualista, aventureira, sem escrúpulos ou pelo menos com frágeis escrúpulos, de políticas por interesses, da ligação - ainda que não imediatamente como ocorria no século XIX - do estudo jurídico com as carreiras públicas estatais. Enfim, o ensino do direito no país segue preso a um conjunto de crenças e fetiches propalados por disciplinas que reafirmam o denominado "senso comum teórico dos juristas" denunciado por Warat ${ }^{33}$, e os cursos jurídicos seguem dando ênfase aos conteúdos de cariz dogmático - que (ainda) assumem posição central nas grades curriculares.

Esta vocação pelo bacharelismo está atrelada a uma vinculação com os cargos públicos e a estabilidade que eles propiciam, e se hoje em dia a corrida pelo diploma jurídico não se dá claramente em função de status social, é abastecida pela quantidade de oportunidades ventiladas pelo tão sonhado diploma: concursos públicos de todas as espécies, consultoria, magistério e até mesmo, em alguns casos, a advocacia. Nesse quadro, a imagem do "profissional de sucesso" projetada - e vendida (como verdadeira mercadoria em um pululante universo de "cursinhos preparatórios para carreiras jurídicas" e congressos realizados em grandes redes de hotéis e resorts, que rendem excelente "selfies" nas redes sociais) - é a do jurista jovem, concursado, que exibe roupas de grifes conhecidas, passa férias no exterior e dirige carros importados. Ele não domina assuntos sociológicos e/ou filosóficos, afinal, o que “cai” mesmo nas provas de concursos são os conteúdos dogmáticos. Nossos medalhões contemporâneos não leem, sequer, as obras machadianas (consideradas apenas como “condição de possibilidade" para

${ }^{32}$ DA MATTA, Roberto. Carnavais, malandros e heróis: para uma sociologia do dilema brasileiro. Rio de Janeiro: Rocco, 1997, p. 28.

${ }^{33}$ WARAT, Luis Alberto. Introdução geral ao direito I. Porto Alegre: Fabris, 1994. 
O ENSINO JURÍDICO BRASILEIRO E A FORMAÇ̃̃O DO “MEDALHÃO" MACHADIANO: EM BUSCA DE ALTERNATIVAS Á LUZ DA PROFANAÇÃO AGAMBENIANA E DA CARNAVALIZAÇÃO WARATIANA

MAIQUEL ÂNGELO DEZORDI WERMUTH JOICE GRACIELA NIELSSON

aprovação vestibular). Estão preocupados apenas com os manuais (inclusive aqueles do tipo “Como passar em provas e concursos") ${ }^{34}$.

Persiste, portanto, nos dias atuais, como uma marca indelével do bacharelismo oitocentista, uma relação negligente do profissional com um projeto mais amplo de sociedade. De acordo com Tércio Ferraz Jr. ${ }^{35}$, nos dias atuais, ao se falar em "Ciência do Direito", no sentido do estudo que se processa nas Faculdades de Direito, há uma forte tendência em “identificá-la com um tipo de produção técnica, destinada apenas a atender às necessidades profissionais (o juiz, o advogado, o promotor) no desempenho imediato de suas funções." Isso conduz à formação de um jurista teórico que, "pela sua formação universitária, foi sendo conduzido a esse tipo de especialização fechada e formalista", marcada por um sentido comum teórico dos juristas, como afirma Streck ${ }^{36}$, que "sufoca as possibilidades interpretativas. Quando submetido à pressão do novo, (re)age institucionalizando a crítica." Nesse contexto, há “possibilidades de dissidências apenas possíveis (delimitadas previamente). Ou seja, no interior do sentido comum teórico, permite-se, difusamente, (apenas) o debate periférico, mediante a elaboração de respostas que não ultrapassem o teto hermenêutico prefixado (horizonte do sentido)."

Em outras palavras, pode-se referir o conceito de "educação bancária", concebido por Paulo Freire ${ }^{37}$ para designar um modelo de ensino que privilegia a repetição e memorização de conteúdos (o docente, por meio da aula essencialmente expositiva, "deposita" conteúdos na “cabeça” dos alunos, os quais serão, nas avaliações, chamados a apresentar o "extrato" do que aprenderam).

\footnotetext{
${ }^{34}$ Em ácida crítica, Lenio Luiz Streck salienta o crescente mercado, no Brasil, dos livros do tipo "Direitos resumidos (e resumidinhos), simplinhos, mastigados (e mastigadinhos), direito Prêt-à-Porter." STRECK, Lenio Luiz. Thays, 18, passa na OAB: o rei está nu! Fracassamos! 2014. Disponível em: <http://www.conjur.com.br/2014-mai-01/senso-incomum-thays-18-passa-oab-rei-nu-fracassamos>. Acesso em 19 set. 2015. Com efeito, para além do "ranço histórico", o Brasil assiste na contemporaneidade a uma crescente "mercantilizacão" do ensino do Direito, em um movimento no qual "a busca desenfreada do lucro pelos empresários da educação, no campo do ensino jurídico, acaba por negar a própria ideia de direito enquanto expressão ética do justo, do equitativo, do certo e do bom." MACHADO, Antônio Alberto. Ensino jurídico e mudança social. 2. ed. São Paulo: Expressão Popular, 2009, p. 103.

${ }^{35}$ FERRAZ JR., Tércio Sampaio. Introdução ao Estudo do Direito: técnica, decisão e dominação. 2. ed. São Paulo: Atlas, 1994, p. 49.

${ }^{36}$ STRECK, Lenio Luiz. Hermenêutica e ensino jurídico em terrae brasilis. Revista da Faculdade de Direito da Universidade Federal do Paraná. Vol. 46, n. 0, 2007, p. 30-31.

${ }^{37}$ FREIRE, Paulo. Pedagogia do oprimido. 27. ed. Rio de Janeiro: Paz e terra, 1987.
} 
ISSN 1981-3694

(DOI): $10.5902 / 1981369419596$

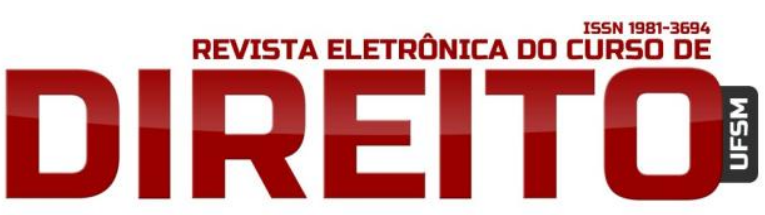

O ENSINO JURÍDICO BRASILEIRO E A FORMAÇÃO DO “MEDALHÃO” MACHADIANO: EM BUSCA DE ALTERNATIVAS Á LUZ DA PROFANAÇÃO AGAMBENIANA E DA CARNAVALIZAÇÃO WARATIANA

MAIQUEL ÂNGELO DEZORDI WERMUTH JOICE GRACIELA NiELSSON

0 diagnóstico de Aguiar $^{38}$ é similar: o autor refere a existência de uma "estruturação pedagógica atrasada" que, combinada com salas de aula lotadas e com pouca exigência acadêmica, acaba por condenar os cursos de Direito do país à formação de "despachantes, que operam perifericamente com as normas, usando seu fraco bom senso, já que não tratam os comandos normativos com um mínimo de rigor", eis que, invariavelmente, o estudo é pautado por textos que, no máximo, referem-se "às vivências pessoais dos docentes, tudo isso iluminado pelas poucas velas de doutrinas ultrapassadas e preconceitos camuflados."

Nesse marco, pode-se afirmar que o paradigma (dogmático) dominante no ensino do direito não permite ao estudante compreender que "na sociedade circulam várias formas de poder, de direito e de conhecimentos que vão muito além do que cabe nos seus postulados." A partir da estratégia de eliminação de qualquer elemento extra-normativo, as faculdades de direito acabam por criar "uma cultura de extrema indiferença ou exterioridade do direito diante das mudanças experimentadas pela sociedade." Isso porque, "enquanto locais de circulação dos postulados da dogmática jurídica, têm estado distantes das preocupações sociais e têm servido, em regra, para a formação de profissionais sem um maior comprometimento com os problemas sociais" - como assevera Boaventura de Sousa Santos ${ }^{39}$.

Em outras palavras, é possível afirmar que as faculdades de Direito, no Brasil, se transformaram - a partir da longa trajetória histórica delineada, comprometida com a manutenção de uma abordagem "asséptica” do fenômeno jurídico - em locais de culto. Com efeito, se historicamente o ensino jurídico no país encontra-se relacionado à questão da imposição do poder, esse processo quase que "alquímico" de separação de qualquer consideração crítica dos conteúdos estudados, a ênfase na dogmática e nos Códigos, presta-se, em última instância, para distanciar, separar, aqueles que ocupam espaços privilegiados de poder - ou os medalhões machadianos - das massas.

Por isso a metáfora do "culto": a partir da obra do filósofo italiano Giorgio Agamben ${ }^{40}$ constata-se, a partir da análise etimológica do termo realizada pelo autor, que religio "não é o que une homens e deuses, mas aquilo que cuida para que se mantenham distintos." Logo, ao estudar o "fenômeno jurídico", por mais paradoxal que isso possa parecer, de modo dissociado

\footnotetext{
${ }^{38}$ AGUIAR, Roberto A. R. de. Habilidades: ensino jurídico e contemporaneidade. Rio de Janeiro: DP\&A, 2004, p. 185.

${ }^{39}$ SANTOS, Boaventura de Sousa. Para uma revolução democrática da justiça. 2. ed. São Paulo: Cortez, 2008, p. 71.

${ }^{40}$ AGAMBEN, Giorgio. Profanações. Trad. Selvino J. Assmann. São Paulo: Boitempo, 2007, p. 66.
} 
O ENSINO JURÍDICO BRASILEIRO E A FORMAÇ̃̃O DO “MEDALHÃO" MACHADIANO: EM BUSCA DE ALTERNATIVAS Á LUZ DA PROFANAÇÃO AGAMBENIANA E DA CARNAVALIZAÇÃO WARATIANA

MAIQUEL ÂNGELO DEZORDI WERMUTH JOICE GRACIELA NIELSSON

da realidade social, os cursos de direito no Brasil historicamente se prestaram ao estabelecimento de uma espécie de "religião" do direito, responsável pela sua separação, pelo seu desligamento, do mundo dos homens (leia-se: não iniciados).

Neste contexto de ensino jurídico enquanto “religião”, pautado pela dogmática e pelo senso comum teórico, "os fenômenos sociais que chegam ao Judiciário passam a ser analisados como meras abstrações jurídicas", de modo que "as pessoas, protagonistas do processo, são transformadas em autor e réu, reclamante e reclamado, e, não raras vezes, 'suplicante' e 'suplicado' [...]." Em outras palavras, “isto significa dizer que os conflitos sociais não entram nos fóruns e nos tribunais graças às barreiras criadas pelo discurso (censor) produzido pela dogmática jurídica dominante", o que gera uma espécie de “objetificação das relações jurídicas" ${ }^{41}$.

Um exemplo que pode ser esclarecedor: quando se estuda, na disciplina de Direito Penal, o delito de homicídio, é comum que a aula seja destinada à interpretação dos dispositivos legais relacionados ao tipo, estabelecendo distinções entre o homicídio simples, privilegiado, qualificado e hediondo (com recurso às lições doutrinárias e jurisprudenciais sobre o tema). Mas essa discussão - pela sua "assepsia" - não permite - até mesmo em razão dos fatores "tempo" versus "ementa a cumprir" - que o professor explore com os alunos questões como: quem é a principal vítima de homicídios no Brasil? Qual o perfil do autor desse tipo de crime? Existem distinções na forma como os autores de homicídios no Brasil são tratados pelas agências do sistema punitivo (ou seja, é possível identificar processos de "refração" entre os crimes cometidos, processados e punidos)? Como se explica o alto grau de homicídios perpetrados pelos próprios órgãos que integram o sistema penal no Brasil? Etc ${ }^{42}$.

É justamente nesse ponto que a tarefa da profanação - proposta na obra agambeniana como condição de possibilidade para romper a separação promovida pela sacralização - se apresenta como primordial e assume o sentido de fazer com que as coisas que saíram da esfera do humano por meio da "consagração" sejam restituídas ao livre uso dos homens. Se a

\footnotetext{
${ }^{41}$ STRECK, Lenio Luiz. Hermenêutica e ensino jurídico em terrae brasilis. Revista da Faculdade de Direito da Universidade Federal do Paraná. Vol. 46, n. 0, 2007, p. 32.

42 Lenio Streck elenca outros exemplos: "o que significa o dispositivo constitucional da igualdade de todos perante a lei' para a imensa maioria da população brasileira? O que significa pacta sunt servanda em um conflito sociojurídico entre incluídos e excluídos (socialmente)?”. STRECK, Lenio Luiz. Hermenêutica e ensino jurídico em terrae brasilis. Revista da Faculdade de Direito da Universidade Federal do Paraná. Vol. 46, n. 0, 2007, p. 31.
} 
O ENSINO JURÍDICO BRASILEIRO E A FORMAÇÃO DO "MEDALHÃO" MACHADIANO: EM BUSCA DE ALTERNATIVAS A LUZ DA PROFANAÇÃO AGAMBENIANA E DA CARNAVALIZAÇÃO WARATIANA

MAIQUEL ÂNGELO DEZORDI WERMUTH JOICE GRACIELA NiELSSON

consagração designa a separação entre a esfera dos deuses e dos homens, etimologicamente, “puro, profano, livre dos nomes sagrados, é o que é restituído ao uso comum dos homens." 43 .

Nesse sentido, a profanação, em Agamben, “designa o ato de restituir ao livre uso e comércio dos homens o que antes fora separado por algum tipo de consagração, interdição, indisponibilidade." ${ }^{44}$. Trata-se, cumpre salientar, de uma tarefa distinta da mera “secularização". Isso porque, na esteira de Agamben"4, a secularização se revela como "uma forma de remoção que mantém intactas as forças, que se restringe a deslocar de um lugar a outro", de forma que "a secularização política de conceitos teológicos (a transcendência de Deus como paradigma do poder soberano) limita-se a transmutar a monarquia celeste em monarquia terrena, deixando, porém, intacto o seu poder."

Já a profanação refere-se à "neutralização daquilo que profana. Depois de ter sido profanado, o que estava indisponível e separado perde a sua aura e acaba restituído ao uso." Assim, enquanto a secularização assegura o poder remetendo-o a um modelo sagrado, a profanação "desativa os dispositivos do poder e devolve ao uso comum os espaços que ele havia confiscado." ${ }^{46}$.

No caso do ensino jurídico, esse ato de profanar pode ser compreendido como uma forma especial de negligência, que ignora a separação operada pela religião, ou melhor, faz dela um uso particular. Profanar não significa apenas a abolição das separações, mas, sobretudo, aprender a fazer delas um novo uso e, até mesmo, brincar com elas. A obra waratiana, no Brasil, pode ser considerada, nesse rumo, um excelente exemplo de profanação: a carnavalização do direito proposta por Warat ${ }^{47}$ representa justamente essa tentativa de evitar que a "culturadetergente" - nomenclatura utilizada pelo autor para designar o empreendimento cultural que representa piamente um pensamento sem sujeira, ou seja, asséptico - penetre o imaginário dos juristas, maculando-o. De acordo com o jurista portenho que optou por viver no Brasil,

[...] o homem se fez tão adito às palavras, está tão intoxicado delas que as converteu em algo mais importante que o real, o símbolo convertido em algo mais importante que do que o que simboliza. Neste momento, a questão é tão

\footnotetext{
${ }^{43}$ AGAMBEN, Giorgio. Profanações. Trad. Selvino J. Assmann. São Paulo: Boitempo, 2007, p. 65.

${ }^{44}$ NASCIMENTO, Daniel Arruda. Do fim da experiência ao fim do jurídico: percurso de Giorgio Agamben. São Paulo: LiberArs, 2012, p. 224.

${ }^{45}$ AGAMBEN, Giorgio. Profanações. Trad. Selvino J. Assmann. São Paulo: Boitempo, 2007, p. 68.

${ }^{46}$ AGAMBEN, Giorgio. Profanações. Trad. Selvino J. Assmann. São Paulo: Boitempo, 2007, p. 68.

${ }^{47}$ WARAT, Luis Alberto. A ciência jurídica e seus dois maridos. 2. ed. Santa Cruz do Sul: EDUNISC, 2000, p. 12.
} 
O ENSINO JURÍDICO BRASILEIRO E A FORMAÇ̃̃̃O DO “MEDALHÃO" MACHADIANO: EM BUSCA DE ALTERNATIVAS Ȧ LUZ DA PROFANAÇÃO AGAMBENIANA E DA CARNAVALIZAÇÃO WARATIANA

MAIQUEL ÂNGELO DEZORDI WERMUTH JOICE GRACIELA NIELSSON

grave que caracteriza os tipos de cultura em que vivemos: a sociedade dos simulacros ${ }^{48}$.

O mestre argentino salienta a necessidade de uma subversão das múltiplas formas com que se apresentam as visões autorizadas de mundo, relacionadas à repressão de qualquer relação livre dos discursos com os acontecimentos, o que representa, na sua visão, "uma luta que requer coragem, astúcia e malandragem", já que voltada à "abolição de toda cosmovisão autorizada e centralizadora (cheia de medo e falsa unidade) do mundo." 49 .

Nesse sentido, a profanação pode assumir a forma de um jogo, que nada mais é que um uso totalmente incongruente do sagrado, uma vez que "a maioria dos jogos que conhecemos deriva de antigas cerimônias sacras, de rituais e de práticas divinatórias que outrora pertenciam à esfera religiosa em sentido amplo" - da mesma forma que o carnaval ${ }^{50}$. Dessa forma, “o jogo libera e desvia a humanidade da esfera do sagrado, mas sem a abolir simplesmente. 0 uso a que o sagrado é devolvido é um uso especial, que não coincide com o consumo utilitarista." Nessa ótica, “da mesma forma que a religio não mais observada, mas jogada, abre a porta para o uso, assim também as potências da economia, do direito e da política, desativadas em jogo, tornamse a porta de uma nova felicidade." ${ }^{51}$

Nesse sentido a proposta do ensino carnavalizado de Warat ${ }^{52}$ :

a carnavalização valoriza o domínio da sexualidade e da brincadeira como espaço de resistência e de ordem social; uma concepção do indivíduo - enquanto representação ideológica do social - que se apóia numa valoração exacerbada da

\footnotetext{
${ }^{48}$ WARAT, Luis Alberto. A ciência jurídica e seus dois maridos. 2. ed. Santa Cruz do Sul: EDUNISC, 2000, p. 19.

49 WARAT, Luis Alberto. A ciência jurídica e seus dois maridos. 2. ed. Santa Cruz do Sul: EDUNISC, 2000, p. 84).

${ }^{50}$ Nascimento traduz a lógica do jogo proposta por Agamben a partir de um elucidativo exemplo: “os jogos espetaculares são em boa medida um exemplo de como nossa cultura escamoteia via subterfúgios mais diversos o âmbito religioso, embora se aproprie de seus dispositivos, sempre operando com mecanismos de separação. 0 nosso mundo secularizado é aquele em que jogos de futebol manifestam um forte desejo de religiosidade, produzindo, sem o admitir abertamente, templos, altares, santos, veste litúrgica, rituais, dízimo, hinos de louvor, exaltação, êxtase, sacrifício, fanatismo." Agamben (2007, p. 67) também explicita a ideia de profanação por meio do jogo a partir de um exemplo: "as crianças, que brincam com qualquer bugiganga que lhes caia nas mãos, transformam em brinquedo também o que pertence à esfera da economia, da guerra, do direito e das outras atividades que estamos acostumados a considerar sérias. Um automóvel, uma arma de fogo, um contrato jurídico transformam-se improvisadamente em brinquedos." NASCIMENTO, Daniel Arruda. Do fim da experiência ao fim do jurídico: percurso de Giorgio Agamben. São Paulo: LiberArs, 2012, p. 224-225.

${ }^{51}$ AGAMBEN, Giorgio. Profanações. Trad. Selvino J. Assmann. São Paulo: Boitempo, 2007, p. 66-67.

52 WARAT, Luis Alberto. A ciência jurídica e seus dois maridos. 2. ed. Santa Cruz do Sul: EDUNISC, 2000, p. 143.
} 
O ENSINO JURÍDICO BRASILEIRO E A FORMAÇ̃̃O DO “MEDALHÃO" MACHADIANO: EM BUSCA DE ALTERNATIVAS A LUZ DA PROFANAÇÃO AGAMBENIANA E DA CARNAVALIZAÇÃO WARATIANA

MAIQUEL ÂNGELO DEZORDI WERMUTH JOICE GRACIELA NIELSSON

razão. A carnavalização é, portanto, uma forma de resistir pelo jogo, e pela dramatização, ao controle social.

Esse modelo seria como um "mergulho no mundo mágico das crianças, para recuperar o sentido dos rabiscos da infância sobre as marcas mortuárias das verdades dos experientes e as descrições adultas."

Nesse ponto, é importante asseverar que "a profanação não restaura simplesmente algo parecido com um uso natural, que preexista à sua separação na esfera religiosa, econômica ou jurídica." Como evidenciado pelo exemplo do jogo, a operação da profanação “é mais astuta e complexa e não se limita a abolir a forma da separação para voltar a encontrar, além ou aquém dela, um uso não contaminado." 54

Um bom exemplo disso pode ser buscado em uma profanação que ocorre na natureza:

[...] o gato que brinca com um novelo como se fosse um rato - exatamente como a criança fazia com antigos símbolos religiosos ou com objetos que pertenciam à esfera econômica - usa conscientemente de forma gratuita os comportamentos próprios da atividade predatória (ou, no caso da criança, próprios do culto religioso ou do mundo do trabalho). Estes não são cancelados, mas, graças à substituição do novelo pelo rato (ou do brinquedo pelo objeto sacro), eles acabam desativados e, desta forma, abertos a um novo e possível uso ${ }^{55}$.

Aqui reside o ponto fundamental: a profanação e o comportamento libertador que the subjaz (como o do gato que brinca com o novelo) reproduzem e ainda expressam gestualmente as formas da atividade da qual se emanciparam. No entanto, esvaziam essas formas de seu sentido e da relação imposta com uma finalidade, promovendo a sua abertura e a sua disponibilização para um novo uso. Trata-se, na visão carnavalizada waratiana ${ }^{56}$, de uma "versão aberta, de uma versão democrática do mundo", na qual "não existem mais fundamentos seguros para definir o lugar de um e de outro." Há, aqui, um duplo processo de libertação: no exemplo do gato, o jogo com o novelo representa a libertação do rato da condição de presa, mas também representa a libertação da atividade predatória do gato do fato de estar necessariamente voltada para a captura e a morte do rato mas, ao mesmo tempo, ele apresenta os mesmos comportamentos que definiam a caça. A perspicácia do gato e a posição de vítima por excelência do rato são subvertidas, transformadas em múltiplas potencialidades.

\footnotetext{
${ }^{53}$ WARAT, Luis Alberto. A ciência jurídica e seus dois maridos. 2. ed. Santa Cruz do Sul: EDUNISC, 2000, p. 161

${ }_{54}^{5 G}$ AGMBEN, Giorgio. Profanações. Trad. Selvino J. Assmann. São Paulo: Boitempo, 2007, p. 74.

${ }^{55}$ AGAMBEN, Giorgio. Profanações. Trad. Selvino J. Assmann. São Paulo: Boitempo, 2007, p. 74.

${ }^{56}$ WARAT, Luis Alberto. A ciência jurídica e seus dois maridos. 2. ed. Santa Cruz do Sul: EDUNISC, 2000, p. 128.
} 
O ENSINO JURÍDICO BRASILEIRO E A FORMAÇ̃̃O DO “MEDALHÃO" MACHADIANO: EM BUSCA DE ALTERNATIVAS A LUZ DA PROFANAÇÃO AGAMBENIANA E DA CARNAVALIZAÇÃO WARATIANA

MAIQUEL ÂNGELO DEZORDI WERMUTH JOICE GRACIELA NIELSSON

$\mathrm{Na}$ proposta de Warat"57, esse "deslocar”, “erotizar”, “diversificar”, “devassar”, “debochar”, “improvisar”, “conflitar” - viabilizados por meio da ideia de profanação agambeniana - afiguram-se como "as artes de um brincar irreverente que não exalta a propriedade, tira as verdades do lugar e dessacraliza hierarquias" 58 . Ou seja, "a cosmovisão carnavalesca abala ou enfrenta aqueles princípios, crenças ou mecanismos que colocam a razão acima da vida." 59 . Trata-se, em última instância, de uma espécie de "revolta" contra o paradigma da distinção, do dever, do método, tão caros ao modelo de ensino tradicional. 0 resultado: a libertação do professor e do aluno de qualquer perspectiva autoritária, imposta, que viabilize o cultivo da polifonia discursiva e, reflexamente, refute qualquer ficção de sociedade ordenada e orgânica ${ }^{60}$ :

[...] a didática carnavalizada visa substituir pelo jogo a compulsão neurótica pelas verdades, a versão fóbica à mobilidade; o apego à certeza do já enxergado, as atitudes altaneiras e etiquetadas, as lições repetindo-se. Tudo como efeito de um ensino socialmente bem estabelecido. 0 jogo substituindo o tédio e a dominação.

[...]

Um dia de aula, um seminário devem ser como um dia de infância: uma alegria vivida ${ }^{61}$.

Deste modo, é possível afirmar que a atividade que resulta da profanação se transforma em um puro meio, o que significa que ela se transforma em "uma prática que, embora conserve tenazmente a sua natureza de meio, se emancipou da sua relação com uma finalidade, esqueceu alegremente o seu objetivo, podendo agora exibir-se como tal, como meio sem fim." ${ }^{62}$ Em síntese: "a criação de um novo uso só é possível ao homem se ele desativar o velho uso,

\footnotetext{
${ }^{57}$ WARAT, Luis Alberto. A ciência jurídica e seus dois maridos. 2. ed. Santa Cruz do Sul: EDUNISC, 2000, p. 143.

58 De acordo com Warat, "a carnavalidade [...] está empenhada em exaltar as formas de saber, menosprezadas pela cultura oficial, como maneira de sabotar os sabotadores." WARAT, Luis Alberto. A ciência jurídica e seus dois maridos. 2. ed. Santa Cruz do Sul: EDUNISC, 2000, p. 141.

${ }^{59}$ WARAT, Luis Alberto. A ciência jurídica e seus dois maridos. 2. ed. Santa Cruz do Sul: EDUNISC, 2000, 2000 , p. 140.

60 “A carnavalizacão permite despojar-nos, pelo jogo, de certas disfunções cientificistas, mostrando-nos um certo jeito mágico de brincar. Uma ousadia que transforma a ciência em prazer, permitindo aceitar os chifres do inconsciente. Aprender é também aceitar as trapaças do id." WARAT, Luis Alberto. A ciência jurídica e seus dois maridos. 2. ed. Santa Cruz do Sul: EDUNISC, 2000, p. 149.

${ }^{61}$ WARAT, Luis Alberto. A ciência jurídica e seus dois maridos. 2. ed. Santa Cruz do Sul: EDUNISC, 2000, p. 150.

${ }^{62}$ Reitera Agamben (2007, p.75) que "profanar não significa simplesmente abolir e cancelar as separações, mas aprender a fazer delas um uso novo, a brincar com elas. A sociedade sem classes não é uma sociedade que aboliu e perdeu toda memória das diferenças de classe, mas uma sociedade que soube desativar seus dispositivos, a fim de tornar possível um novo uso, para transformá-las em meios puros."
} 
tornando-o inoperante." E mais: "as formas desse uso só poderão ser inventadas de maneira coletiva."63.

Portanto, a missão que se apresenta para todos os envolvidos com o ensino jurídico brasileiro - professores, alunos, pesquisadores - é o resgate da possibilidade de um "novo uso" do ensino jurídico, capaz de subverter, pela via da resistência e da carnavalização waratiana, o modelo tradicional da sacralidade, renegando qualquer tipo de ambição unificadora das significações e rompendo, dessa forma, com o nexo historicamente estabelecido entre saber jurídico e poder, devolvendo o estudo jurídico à condição de um espaço privilegiado de transformação do status quo, em detrimento da formação dos “medalhões” machadianos.

\section{CONCLUSÃO}

O conto "Teoria do Medalhão", escrito por Machado de Assis em 1881, apresenta uma crítica contundente à sociedade brasileira. Em primeiro lugar, porque retrata a ideia de que o indivíduo precisa se auto-aniquilar em favor da construção de uma "imagem" social considerada privilegiada - representada pela figura do "medalhão"; em segundo lugar, porque salienta os traços patriarcais ("Não te ponhas com denguices, e falemos como dois amigos sérios") e rigidamente hierarquizados ("Isto é a vida; não há planger, nem imprecar, mas aceitar as coisas integralmente, com seus ônus e percalços, glórias e desdouros”) de nossa sociedade, apresentando um pai que, após o jantar comemorativo dos 21 anos do filho, impõe-lhe, de forma irônica, algumas dicas comportamentais para alcançar o status de medalhão, as quais são aceitas de modo passivo e inquestionável pelo filho.

Dentre essas “dicas”, estão a necessidade de anulação dos gostos e opiniões pessoais, a neutralidade diante dos assuntos, a limitação do vocabulário ("'Filosofia da história', por exemplo, é uma locução que deves empregar com frequência, mas proíbo-te que chegues a outras conclusões que não sejam as já achadas por outros. Foge a tudo que possa cheirar a reflexão, originalidade, etc., etc.") e o humor simples no lugar da ironia, que sempre requer maior sofisticação ("Usa antes a chalaça, a nossa boa chalaça amiga, gorducha, redonda, franca, sem biocos, nem véus, que se mete pela cara dos outros, estala como uma palmada, faz pular o sangue nas veias, e arrebentar de riso os suspensórios"). 0 pai termina a conversa admitindo

${ }^{63}$ AGAMBEN, Giorgio. Profanações. Trad. Selvino J. Assmann. São Paulo: Boitempo, 2007, p. 74-75. 
ISSN 1981-3694

(DOI): $10.5902 / 1981369419596$

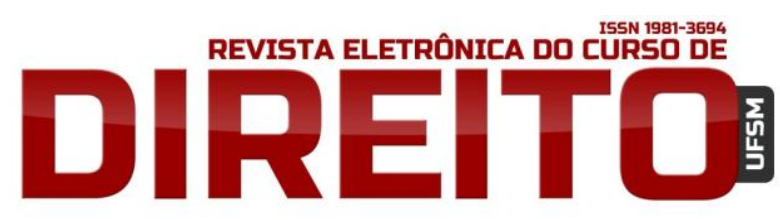

O ENSINO JURÍDICO BRASILEIRO E A FORMAÇÃO DO “MEDALHÃO” MACHADIANO: EM BUSCA DE ALTERNATIVAS À LUZ DA PROFANAÇÃO AGAMBENIANA E DA CARNAVALIZAÇÃO WARATIANA

MAIQUEL ÂNGELO DEZORDI WERMUTH JOICE GRACIELA NIELSSON

que suas palavras têm certa semelhança com a obra clássica de Maquiavel, e despede-se do filho ("Rumina bem o que te disse, meu filho. Guardadas as proporções, a conversa desta noite vale o Príncipe de Machiavelli. Vamos dormir”).

As “lições" transmitidas pela personagem do pai machadiano ao filho foram utilizadas, no presente texto, como metáfora para uma análise da forma como o ensino jurídico, no Brasil, historicamente esteve relacionado à criação de espaços privilegiados de poder, imposto por meio do saber representado pela "cultura do bacharelismo", responsável pela criação dos “medalhões" de nossa sociedade. Como se procurou demonstrar na primeira parte do texto, o saber jurídico em terrae brasilis sempre representou um "capital simbólico", responsável pela manutenção e reprodução de um modelo de organização social rigidamente hierarquizado, pautado pela demarcação de espaços de poder para algumas "pessoas" e pela criação de estratégias de controle e invisibilização social de determinados “indivíduos" - na análise de Roberto DaMatta. As hegemonias conservadoras brasileiras se utilizaram, historicamente, do saber para impor poder, sustentando, na base do açoite, teorias "importadas" da Europa e “temperadas" com adereços tupiniquins, de modo a manter incólume o modelo de organização social aqui vigente.

Nesse sentido, pode-se afirmar que o ensino jurídico, a partir dessas estratégias, sempre esteve voltado à "sacralização" de conceitos e institutos cuja função é justamente separar os "iniciados" na ciência do direito dos "não iniciados". Aos primeiros, sempre coube a ocupação dos cargos relacionados à administração pública, dando continuidade a um modelo de organização pautado pelo revezamento, no poder, das oligarquias agrícolas do período colonial que apenas transladaram para os centros urbanos o "modo-de-ser" dos grandes latifúndios.

Esses processos de sacralização do saber jurídico implicou o afastamento de uma compreensão efetivamente emancipatória do direito, no marco do que Warat, em lição clássica, denominou como senso comum teórico dos juristas. Os currículos dos cursos de Direito do país sempre privilegiaram uma abordagem do "fenômeno jurídico" de forma asséptica e com ênfase nos conteúdos voltados à dogmática. Na contemporaneidade, as faculdades de Direito ainda podem ser consideradas instâncias de preparação dos bacharéis para os cargos públicos - já que a estabilidade que esses cargos propiciam é justamente a "propaganda" utilizada para "vender" mais e mais vagas no pululante universo de cursos de graduação em direito no Brasil (sem mencionar o número incomensurável de “cursinhos preparatórios” para concursos). 
ISSN 1981-3694

(DOI): $10.5902 / 1981369419596$

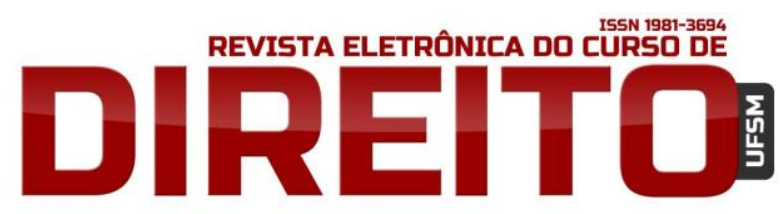

O ENSINO JURÍDICO BRASILEIRO E A FORMAÇÃO DO “MEDALHÃO” MACHADIANO: EM BUSCA DE ALTERNATIVAS À LUZ DA PROFANAÇÃO AGAMBENIANA E DA CARNAVALIZAÇÃO WARATIANA

MAIQUEL ÂNGELO DEZORdI WeRMUTH JOICE GRACIELA NIELSSON

Nesse sentido, a ideia de profanação cunhada pelo filósofo italiano Giorgio Agamben foi abordada, na segunda parte do texto, enquanto condição de possibilidade para um "novo uso" do ensino jurídico. Entende-se que a ideia de profanação possui uma força capaz de subverter, pela via da resistência, o modelo tradicional da sacralidade responsável pela formação de meros “medalhões”, ou seja, de sujeitos “castrados”, dos quais se exige uma postura neutra diante dos assuntos abordados em sala de aula.

A proposta de "carnavalização" do ensino jurídico, resgatada na obra waratiana, foi utilizada, então, para demonstrar como um ensino comprometido com a ideia do "jogo" - ou seja, do deslocamento, da erotização, da diversificação, do deboche e do conflito - pode se transformar em um modelo emancipador, que retira as "verdades" do lugar ao dessacralizar as hierarquias que subjazem à lógica da formação dos "medalhões". A "cosmovisão carnavalesca" waratiana, apresenta-se, então como estratégia para que a "profanação" agambeniana viceje, de modo a libertar professores e alunos de qualquer perspectiva autoritária, refutando ficções de sociedade pautadas pela ideia de “ordem e progresso". Brincar com o direito, explorando suas diversas potencialidades, profanando o seu "culto", apresenta-se, nesse sentido, como possibilidade de rompimento do nexo historicamente estabelecido no Brasil entre saber e poder, devolvendo o estudo jurídico à condição de um espaço privilegiado de transformação do status quo, em detrimento da formação dos “medalhões” machadianos.

\section{REFERÊNCIAS}

ADORNO, Sérgio França. Aprendizes do Poder: o bacharelismo liberal na política brasileira. Rio de Janeiro: Paz e Terra, 1998.

AGAMBEN, Giorgio. Profanações. Trad. Selvino J. Assmann. São Paulo: Boitempo, 2007.

AGUIAR, Roberto A. R. de. Habilidades: ensino jurídico e contemporaneidade. Rio de Janeiro: DP\&A, 2004.

BOSI, Alfredo. Machado de Assis: o enigma do olhar, São Paulo: Martins Fontes, 2007.

CARVALHO, José Murilo. Cidadania no Brasil: o longo caminho, Rio de Janeiro: Civilização Brasileira, 2002.

CARVALHO, José Murilo. A Construção da Ordem. Rio de Janeiro: Civilização Brasileira, 2003. 
ISSN 1981-3694

(DOI): $10.5902 / 1981369419596$

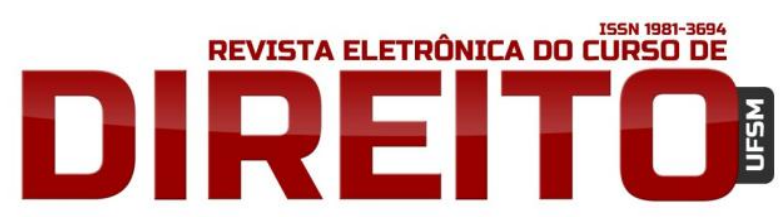

O ENSINO JURÍDICO BRASILEIRO E A FORMAÇÃO DO “MEDALHÃO” MACHADIANO: EM BUSCA DE ALTERNATIVAS À LUZ DA PROFANAÇÃO AGAMBENIANA E DA CARNAVALIZAÇÃO WARATIANA

MAIQUEL ÂNGELO DEZORdI WeRMUTH JOICE GRACIELA NIELSSON

CHALHOUB, Sidney. Trabalho, lar e botequim: o cotidiano dos trabalhadores no Rio de Janeiro da belle époque. 2. ed. Campinas: UNICAMP, 2001.

DA MATTA, Roberto. Carnavais, malandros e heróis: para uma sociologia do dilema brasileiro. Rio de Janeiro: Rocco, 1997.

FAORO, Raymundo. Os Donos do Poder: formação do patronato Político brasileiro. 3. ed. São Paulo: Globo, 2001.

FERNANDES, Pádua. Machado de Assis e o olhar irônico no país dos bacharéis. Revista Ética e Filosofia Política. n. 14, vol. 2, 2011.

FERRAZ JR., Tércio Sampaio. Introdução ao Estudo do Direito: técnica, decisão e dominação. 2. ed. São Paulo: Atlas, 1994.

FOUCAULT, Michel. Microfísica do poder. 18. ed. São Paulo: Graal, 2003.

FREIRE, Paulo. Pedagogia do oprimido. 27. ed. Rio de Janeiro: Paz e terra, 1987.

GADAMER, Hans-Georg. Verdade e Método: traços fundamentais de uma hermenêutica filosófica. 4. ed. Tradução de Flávio Paulo Meurer. Petrópolis: Vozes, 2002, vol. I.

HEIDEGGER, Martin. A essência da linguagem. IN: A Caminho da Linguagem. Tradução de Marcia Sá Cavalcante Schuback. Petrópolis: Vozes, 2003.

HOLANDA, Sérgio Buarque de. Raízes do Brasil. 26a . ed. São Paulo: Companhia das Letras, 1995.

. Raízes do Brasil. 26. ed. 28. reimpr. São Paulo: Companhia das Letras, 2007.

MACHADO, Antônio Alberto. Ensino jurídico e mudança social. 2. ed. São Paulo: Expressão Popular, 2009.

MACHADO DE ASSIS, Obra completa, em quatro volumes. Org. A. Leite Neto, A. Lima Cecília, H. Jahn, Rio de Janeiro: Nova Aguilar, vol. II e IV, 2008.

NASCIMENTO, Daniel Arruda. Do fim da experiência ao fim do jurídico: percurso de Giorgio Agamben. São Paulo: LiberArs, 2012.

NEDER, Gizlene; CERQUEIRA FILHO, Gisálio. Criminologia e Poder Político: sobre direitos, história e ideologia. Rio de Janeiro: Lumen Juris, 2006.

NEDER, Gizlene. Iluminismo jurídico-penal luso-brasileiro: obediência e submissão. 2. ed. Rio de Janeiro: Revan, 2007.

. Cultura, poder e violência. Revista Latinoamericana de Psicopatologia Fundamental. São Paulo, n. 1. p. 17-30, 2009. 
ISSN 1981-3694

(DOI): $10.5902 / 1981369419596$

REVISTA ELETRÔNICA DO CURSD DE

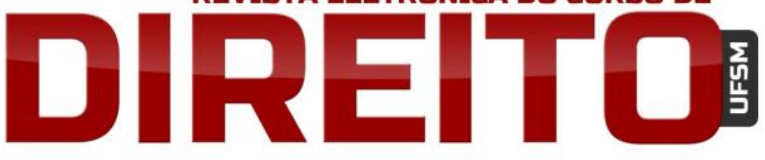

O ENSINO JURÍDICO BRASILEIRO E A FORMAÇÃO DO “MEDALHÃO” MACHADIANO: EM BUSCA DE ALTERNATIVAS A LUZ DA PROFANAÇÃO AGAMBENIANA E DA CARNAVALIZAÇÃO

MAIQUEL ÂNGELO DEZORDI WERMUTH JOICE GRACIELA NIELSSON

RODRIGUES, Horário Wanderlei. Ensino Jurídico: saber e poder. 1. ed. São Paulo: Acadêmica, 1988.

SANTOS, Boaventura de Sousa. Para uma revolução democrática da justiça. 2. ed. São Paulo: Cortez, 2008.

STRECK, Lenio Luiz. Hermenêutica e ensino jurídico em terrae brasilis. Revista da Faculdade de Direito da Universidade Federal do Paraná. Vol. 46, n. 0, p. 27-50, 2007.

. Thays, 18, passa na OAB: o rei está nu! Fracassamos! 2014. Disponível em: <http://www.conjur.com.br/2014-mai-01/senso-incomum-thays-18-passa-oab-rei-nufracassamos>. Acesso em 19 set. 2015.

WARAT, Luis Alberto. Introdução geral ao direito I. Porto Alegre: Fabris, 1994.

. A ciência jurídica e seus dois maridos. 2. ed. Santa Cruz do Sul: EDUNISC, 2000.

WOLKMER, Antônio Carlos. História do Direito no Brasil. 2. ed. Rio de Janeiro: Forense, 2001.

Recebido em: 24.09.2015 / Revisões requeridas em: 26.02.2016 / Aprovado em: 15.03.2016 